\title{
Role of alternative oxidase pathway in protection against drought-induced photoinhibition in pepper leaves
}

\author{
W.H. HU, ${ }^{*}$, X.H. YAN ${ }^{*}$, Y. HE ${ }^{* *}$, and X.L. YE* \\ School of Life Sciences, Jinggangshan University, Ji'an, 343009, China* \\ Jiujiang Agricultural Bureau, Jiujiang, 332000, China ${ }^{* *}$
}

\begin{abstract}
The aim of this study was to assess the impact of the mitochondrial alternative oxidase (AOX) pathway on energy metabolism in chloroplasts, and evaluate the importance of the AOX in alleviating drought-induced photoinhibition in pepper (Capsicum annuum L.). Inhibition of AOX pathway decreased photosynthesis and increased thermal energy dissipation in plants under normal conditions. It indicated that AOX pathway could influence chloroplast energy metabolism. Drought reduced carbon assimilation. Photoinhibition was caused by excess of absorbed light energy in spite of the increase of thermal energy dissipation and cyclic electron flow around PSI (CEF-PSI). Upregulation of AOX pathway in leaves experiencing drought would play a critical role in protection against photoinhibition by optimization of carbon assimilation and PSII function, which would avoid over-reduction of photosynthetic electron transport chain. However, inhibition of AOX pathway could be compensated by increasing the thermal energy dissipation and CEF-PSI under drought stress, and the compensation of CEF-PSI was especially significant.
\end{abstract}

Additional key words: alternative oxidase pathway; Capsicum annuum L; chlorophyll fluorescence; drought; photoinhibition; photosynthesis.

\section{Introduction}

Photosynthesis includes photochemical reactions and carbon assimilation (Raghavendra and Padmasree 2003). Photosynthesis captures light energy to produce ATP and NADPH, which is provided to the Calvin cycle as reducing power (Allakhverdiev 2011). The production and nocsumption of ATP and NADPH must be balanced to prevent photoinhibition or photodamage (Walker et al. 2014). However, excess light energy would result in the accumulation of reducing equivalents in the form of NADPH generated by photochemical reactions and be assumed to produce reactive oxygen species (Foyer et al. 2002, Ort and Baker 2002, Mohanty et al. 2007, Zhang et al. 2011). Accumulation of reducing equivalents in the chloroplasts causes the over-reduction of the photosynthetic electron transport chain and may result in generation of reactive oxygen species, leading to photoinhibition (Yoshida et al. 2007). To counteract photoinhibition, plants have evolved photoprotective mechanisms in chloroplast including thermal energy dissipation (Demmig-Adams and Adams 1996, Song et al. 2011), cyclic electron flow around PSII/PSI (Allakhverdiev et al. 1997, Walker et al. 2014), and water-water cycle (Asada 1999). While such intra-chloroplastic defense systems have been studied extensively, little is known about the extra-chloroplastic defense systems (Yoshida et al. 2007).

As the center of energy metabolism, mitochondrial respiration is thought to play roles in optimizing photosynthesis, especial under stress conditions (Raghavendra and Padmasree 2003, Yoshida et al. 2006, Feng et al. 2015). Reducing equivalents generated in the chloroplasts

\footnotetext{
Received 30 September 2017, accepted 7 February 2018, published as online-first 21 June 2018. ${ }^{+}$Corresponding author; phone.: 0086-7968110393, fax: 0086-7968100493, e-mail: huwenhai@jgsu.edu.cn

Abbreviations: AOX - alternative oxidase; AQY - apparent quantum yield; CEF-PSI - cyclic electron flow around PSI; DM - dry mass; ETR - photosynthetic electron transport rate; $F_{0}-$ minimal fluorescence yield of the dark-adapted state; $F_{m}-$ maximal fluorescence yield of the dark-adapted state; FM - fresh mass; $F_{v} / F_{m}-$ maximal quantum yield of PSII photochemistry; LSP photosynthetic light-saturation points; NPQ - nonphotochemical quenching coefficient; $\mathrm{P}_{\mathrm{m}}$ - maximal P700 changes; $P_{\max }$ - maximum net photosynthetic rate; $P_{\mathrm{N}}$ - net photosynthetic rate; PEG - polyethylene glycol; qP - photochemical quenching coefficient; RLCs rapid light curves; RWC - relative water content; SHAM - salicylhydroxamic acid; TM - turgid mass; $\mathrm{V}_{\mathrm{KCN}}$ - AOX pathway capacity; $\mathrm{V}_{\mathrm{t}}$ - total respiration rate; $\Phi_{\mathrm{PSI}}$ - photochemical quantum yield of PSI; $\Phi_{\text {PSII }}$ - effective quantum yield of PSII photochemistry. Acknowledgements: This work was supported by National Natural Science Foundation of China (31460513).
} 
may be transported to the cytosol via malate/oxaloacetate shuttle and used in other cell compartments such as mitochondria (Nunes-Nesi et al. 2008, Hu et al. 2017). Alternative oxidase (AOX), the unique terminal oxidase in plant mitochondria, accepts electrons directly from ubiquinol and reduces $\mathrm{O}_{2}$ to $\mathrm{H}_{2} \mathrm{O}$ without proton translocation across inner membrane of mitochondria (Dahal et al. 2014). Therefore, mitochondrial alternative oxidase electron transport pathway (AOX pathway) is engaged in the dissipation of excess reducing equivalents from chloroplasts via malate/oxaloacetate shuttle, and may play a particular role in protecting plants from photoinhibition (Yoshida et al. 2007, Dahal et al. 2014). Zhang et al. (2012) observed that inhibition of the AOX pathway by AOX inhibitors (salicylhydroxamic acid, SHAM) decreased the initial activities of NADP-MDH (NADPmalate dehydrogenase) in Rumex K-1 leaves under intense light, which resulted in the rapid accumulation of NADPH in chloroplasts and the restriction of the photosynthetic linear electron flow. Compared to a wild type, aox la mutant exhibited a lower net $\mathrm{CO}_{2}$ assimilation rate and NADP-MDH activity, which was accompanied by a lower maximum electron transport rate and quantum yield of PSII, and higher excitation pressure on PSII and nonphotochemical quenching in chloroplasts (Gandin et al. 2012). The amounts of AOX protein and AOX pathway activities in pgr 5 and crr2-2, Arabidopsis thaliana mutants defective in cyclic electron flow around PSI (CEF-PSI), were higher than those in the wild type (Yoshida et al. 2007). These results suggest that mitochondrial AOX pathway and intrachloroplastic defense systems interact with each other and protect against photoinhibition together.

\section{Materials and methods}

Plant materials: Pepper (Capsicum annuum L. cv. Caola No. 9) was used for this experiment. The seeds were sown in a medium containing a mixture of grass peat and perlite $(8: 2, \mathrm{v} / \mathrm{v})$ in pots $(30 \times 30 \mathrm{~cm})$ placed in a greenhouse. Plants at the 20-leaf stage were transferred into a container filled with $500 \mathrm{ml}$ of Enshi nutrient solution ( $\mathrm{Yu}$ and Matsui 1997). The environmental condition were as follows: the temperature range approximately $18-28^{\circ} \mathrm{C}$, the maximum PAR was approximately $800 \mu \mathrm{mol}\left(\right.$ photon) $\mathrm{m}^{-2} \mathrm{~s}^{-1}$.

Experimental design: SHAM pretreatment and waterrestriction treatment started when plants were cultured in the nutrient solution for one week. Plants were sprayed with 0 or $1 \mathrm{mM}$ SHAM solutions, respectively, for $4 \mathrm{~h}$ in a dark room. Then, half of 0 and $1 \mathrm{mM}$ SHAM-pretreated plants was transferred into $15 \%$ polyethylene glycol (PEG 6000) solution with Enshi nutrient under the greenhouse conditions. The four treatments employed were:
Drought is a major abiotic stress and adversely restricts crop growth, development, and productivity (Boyer 1982). Drought inhibits leaf net photosynthetic rate because of stomatal limitation or/and nonstomatal limitation (Yin et al. 2005, Jia et al. 2008, Erice et al. 2011), which leads to reduced utilization of absorbed light energy in chloroplasts (Ort and Baker 2002, Hu et al. 2017). This results in imbalance between the light absorption and energy utilization in chloroplasts (Ivanov et al. 2008). Drought increased the amount of leaf AOX protein and also enhanced the rate of AOX pathway capacity in pea leaves (Taylor et al. 2002). Dahal et al. (2014, 2015) observed that knockdown of AOX increased the susceptibility of tobacco to a drought-induced biochemical limitation of photosynthesis, while AOX overexpression reduced this susceptibility. Upregulation of the AOX pathway protects the photosynthetic electron transport chain from harmful effects of excess light during drought in wheat leaves (Bartoli et al. 2005). These results indicate that AOX pathway would have influence on defense systems and maintain the energy balance in chloroplasts via malate/ oxaloacetate shuttle under drought, however, the interactions of mitochondrial AOX pathway with chloroplast energy metabolism have not been fully elucidated.

In the present work, we examined the effects of the inhibition of AOX pathway by SHAM on the gas exchange and chlorophyll (Chl) fluorescence in pepper leaves under drought conditions. The aim of this study was to evaluate the impact of the AOX pathway on energy metabolism in chloroplasts. Photoprotection mechanisms of the AOX pathway were discussed.

\begin{tabular}{ll}
\hline Treatment & Solution \\
\hline Control & Enshi nutrient solution/ \\
& 0 mM SHAM pretreatment \\
SHAM & Enshi nutrient solution/ \\
& $1 \mathrm{mM}$ SHAM pretreatment \\
PEG & $15 \%$ PEG6000 solution with Enshi/ \\
& $0 \mathrm{mM}$ SHAM-pretreatment \\
PEG + SHAM & $15 \%$ PEG6000 solution with Enshi/ \\
& $1 \mathrm{mM}$ SHAM-pretreatment \\
\hline
\end{tabular}

The leaf relative water content, alternative pathway respiration, net photosynthetic rate $\left(P_{\mathrm{N}}\right)$ light-response curves, and $\mathrm{Chl}$ fluorescence in pepper leaves were measured $4 \mathrm{~d}$ after treatments.

Leaf water status: Leaf relative water content (RWC) was determined as described by Zandalinas et al. (2016). 
Leaves were weighed to obtain fresh mass (FM). Then, leaves were placed in a beaker with water and kept overnight in the dark, allowing leaves to become fully hydrated. Leaves were reweighed to obtain turgid mass (TM) and dried at $80^{\circ} \mathrm{C}$ for $48 \mathrm{~h}$ to obtain dry mass (DM). Finally, RWC was calculated as:

$\mathrm{RWC}=[(\mathrm{FM}-\mathrm{DM}) /(\mathrm{TM}-\mathrm{DM})] \times 100$.

Respiration rate was measured using a Clark-type oxygen electrode (Oxygraph-lab, Hansatech, UK) at $25^{\circ} \mathrm{C}$ according to $\mathrm{Hu}$ et al. (2017). The samples $(0.1 \mathrm{~g}$ fresh mass) were kept in the dark for 30 min before respiration measurements were carried out. To assess the maximum capacity of the AOX pathway, the cytochrome $c$ pathway was inhibited with $1 \mathrm{mM} \mathrm{KCN}$. The AOX pathway capacity $\left(\mathrm{V}_{\mathrm{KCN}}\right)$ was defined as $\mathrm{O}_{2}$ uptake rate in the presence of $\mathrm{KCN}$.

Net photosynthetic rate in response to light $\left(P_{\mathrm{N}}-\mathrm{PAR}\right.$ curve): $P_{\mathrm{N}}$-PAR curve was measured using an $L I-6400 X T$ (LI-COR Biosciences, Lincoln, NE, USA). During the measurements, the air temperature, relative humidity, and $\mathrm{CO}_{2}$ concentration inside the IRGA chamber were maintained at $30^{\circ} \mathrm{C}, 60 \%$, and $380 \mu \mathrm{mol} \mathrm{mol}{ }^{-1}$. $P_{\mathrm{N}}$ was determined at 14 levels of PAR $[1,600 ; 1,400 ; 1,000 ; 800,600$, 400, 200, 150, 120, 100, 50, 20,0 $\mu \mathrm{mol}$ (photon) $\mathrm{m}^{-2} \mathrm{~s}^{-1}$ ]. The leaf was exposed to $1,600 \mu \mathrm{mol}$ (photon) $\mathrm{m}^{-2} \mathrm{~s}^{-1}$ for $1,200 \mathrm{~s}$ before $P_{\mathrm{N}}$ was determined, thereafter, the leaf was exposed to series of decreasing light intensities for $600 \mathrm{~s}$ at each light level. The apparent quantum yield (AQY), maximum net photosynthetic rate $\left(P_{\max }\right)$, photosynthetic light-saturation points (LSP) were analyzed with $P_{\mathrm{N}}-\mathrm{PAR}$ response curve according to Ye (2007).

\section{Results}

RWC, $\mathbf{V}_{\mathbf{K C N}}, \mathbf{F}_{\mathbf{v}} / \mathbf{F}_{\mathbf{m}}$ and $\mathbf{P}_{\mathbf{m}}$ : Plants under normal condition (control) showed RWC of $92.2 \pm 1.0 \%$, while drought (15\% PEG treatment) significantly decreased RWC to values of $55.1 \pm 2.9 \%$. The total respiration rates $\left(\mathrm{V}_{\mathrm{t}}\right)$ in the leaves under normal and drought condition were similar, but the AOX pathway capacity $\left(\mathrm{V}_{\mathrm{KCN}}\right)$ increased by $34.6 \%$ in leaves under drought condition. SHAM
Simultaneous measurements of $\mathrm{Chl}$ fluorescence and P700: Chl fluorescence and P700 were synchronously measured with the Fluo $+P 700$ Measuring Mode of the Dual-PAM-100/F (Walz, Effeltrich, Germany) according to instruction manual for DUAL-PAM-100. After $30 \mathrm{~min}$ of adaptation in complete darkness, the minimal fluorescence yield of the dark-adapted state $\left(\mathrm{F}_{0}\right)$ and maximal fluorescence yield of the dark-adapted state $\left(\mathrm{F}_{\mathrm{m}}\right)$ were measured. An actinic light $\left[190 \mu \mathrm{mol}\right.$ (photon) $\mathrm{m}^{-2} \mathrm{~s}^{-1}$ ] was then switched on and a saturation pulse $[12,000 \mu \mathrm{mol}$ (photon) $\mathrm{m}^{-2} \mathrm{~s}^{-1}$ ] was applied at regular intervals $(20 \mathrm{~s})$ during actinic light illumination period for induction curves of Chl fluorescence and P700 parameters. RLCs (rapid light curves) was also determined after induction curves. Sample was illuminated stepwise at increasing light intensities [from 11 to $1,450 \mu \mathrm{mol}$ (photon) $\mathrm{m}^{-2} \mathrm{~s}^{-1}$. Saturation pulse was applied at the end of each light step (illumination time was $10 \mathrm{~s}$ ) for determination of $\mathrm{Chl}$ fluorescence and P700 parameters. The determined parameters included: the maximal P700 changes $\left(\mathrm{P}_{\mathrm{m}}\right)$, maximal quantum yield of PSII photochemistry $\left(\mathrm{F}_{\mathrm{v}} / \mathrm{F}_{\mathrm{m}}\right)$, photochemical quantum yield of PSI $\left(\mathrm{Y}_{(\mathrm{I})}\right)$, effective quantum yield of PSII photochemistry $\left(\Phi_{\mathrm{PSII}}\right)$, photochemical quenching coefficient ( $\left.\mathrm{q}_{\mathrm{P}}\right)$, nonphotochemical quenching coefficient (NPQ), and photosynthetic electron transport rate (ETR). The CEF-PSI were estimated by the $\mathrm{ETR}_{(\mathrm{I})} / \mathrm{ETR}_{(\mathrm{II})}$ (Yamori et al. 2011).

Statistical analysis: The results were reported as means with standard error. The significance of results was checked by using the least-significant difference (LSD) test at $P<0.05$ with SPSS 11.5 for Windows (SPSS Inc. Chicago, IL, USA) via one-way analysis of variance (ANOVA).

$(1 \mathrm{mM})$ inhibited $\mathrm{V}_{\mathrm{KCN}}$ by about $44.8 \%$ in leaves from both normal and drought conditions. Drought induced the decrease of $F_{v} / F_{m}$, which was aggravated by SHAM treatment. However, there was little change in $\mathrm{F}_{\mathrm{v}} / \mathrm{F}_{\mathrm{m}}$ when the AOX pathway was inhibited by SHAM at normal conditions. There was also little change in $\mathrm{P}_{\mathrm{m}}$ in leaves under four treatment conditions (Table 1).

Table 1. Effects of PEG and SHAM on the relative water content (RWC), total respiration rate $\left(\mathrm{V}_{\mathrm{t}}\right)$, AOX pathway capacity $\left(\mathrm{V}_{\mathrm{KCN}}\right)$, maximal quantum yield of PSII photochemistry $\left(\mathrm{F}_{\mathrm{v}} / \mathrm{F}_{\mathrm{m}}\right)$ and maximal P700 changes $\left(\mathrm{P}_{\mathrm{m}}\right)$ of pepper leaves after four days of treatment. Data are the means of independent measurements of five replicates with standard errors. Values followed by different letters are significant at $0.05 \%$ level.

\begin{tabular}{lcccc}
\hline & Control & SHAM & PEG & PEG + SHAM \\
\hline RWC $[\%]$ & $92.02 \pm 0.54^{\mathrm{a}}$ & $92.45 \pm 0.41^{\mathrm{a}}$ & $55.05 \pm 1.64^{\mathrm{b}}$ & $55.17 \pm 1.11^{\mathrm{b}}$ \\
$\mathrm{V}_{\mathrm{t}}\left[\mu \mathrm{mol}\left(\mathrm{O}_{2}\right) \mathrm{g}^{-1}(\mathrm{FM}) \mathrm{h}^{-1}\right]$ & $26.7 \pm 0.4^{\mathrm{a}}$ & $19.3 \pm 0.3^{\mathrm{c}}$ & $27.2 \pm 0.4^{\mathrm{a}}$ & $22.8 \pm 0.2^{\mathrm{b}}$ \\
$\mathrm{V}_{\mathrm{KCN}}\left[\mu \mathrm{mol}\left(\mathrm{O}_{2}\right) \mathrm{g}^{-1}(\mathrm{FM}) \mathrm{h}^{-1}\right]$ & $10.7 \pm 0.4^{\mathrm{b}}$ & $5.8 \pm 0.2^{\mathrm{d}}$ & $14.4 \pm 0.7^{\mathrm{a}}$ & $8.1 \pm 0.3^{\mathrm{c}}$ \\
$\mathrm{F}_{\mathrm{v}} / \mathrm{F}_{\mathrm{m}}$ & $0.840 \pm 0.007^{\mathrm{a}}$ & $0.831 \pm 0.009^{\mathrm{a}}$ & $0.806 \pm 0.004^{\mathrm{b}}$ & $0.764 \pm 0.006^{\mathrm{c}}$ \\
$\mathrm{P}_{\mathrm{m}}$ & $0.452 \pm 0.003^{\mathrm{a}}$ & $0.454 \pm 0.002^{\mathrm{a}}$ & $0.456 \pm 0.003^{\mathrm{a}}$ & $0.454 \pm 0.001^{\mathrm{a}}$ \\
\hline
\end{tabular}


Gas-exchange characteristics: Drought significantly decreased $P_{\mathrm{N}}, P_{\max }$, LSP, and AQY. SHAM treatment aggravated the decrease of $P_{\mathrm{N}}, P_{\max }$, LSP, and AQY in leaves under normal and drought conditions (Fig. 3, Table 2).

RLCs of Chl fluorescence parameters: Following increases of light intensity, values of $\Phi_{\mathrm{PSII}}$ and $\mathrm{q}_{\mathrm{P}}$ decreased, however, NPQ and $\mathrm{ETR}_{(\mathrm{I})} / \mathrm{ETR}_{(\mathrm{II})}$ increased.
Drought induced the decreases of $\Phi_{\mathrm{PSII}}$ and the increases of NPQ and $\mathrm{ETR}_{(\mathrm{I})} / \mathrm{ETR}_{(\mathrm{II})}$, however, there was no obvious change in qP. SHAM treatment aggravated the decreases of $\Phi_{\mathrm{PSII}}$ and $\mathrm{q}_{\mathrm{P}}$, but induced the increase of NPQ in leaves under normal and drought conditions. There was a slight increase of $\mathrm{ETR}_{(\mathrm{I})} / \mathrm{ETR}_{(\mathrm{II})}$ in leaves under drought, however, SHAM treatment significantly increased $\mathrm{ETR}_{(\mathrm{I})} / \mathrm{ETR}_{(\mathrm{II})}$ in drought-treated leaves (Fig. 1).

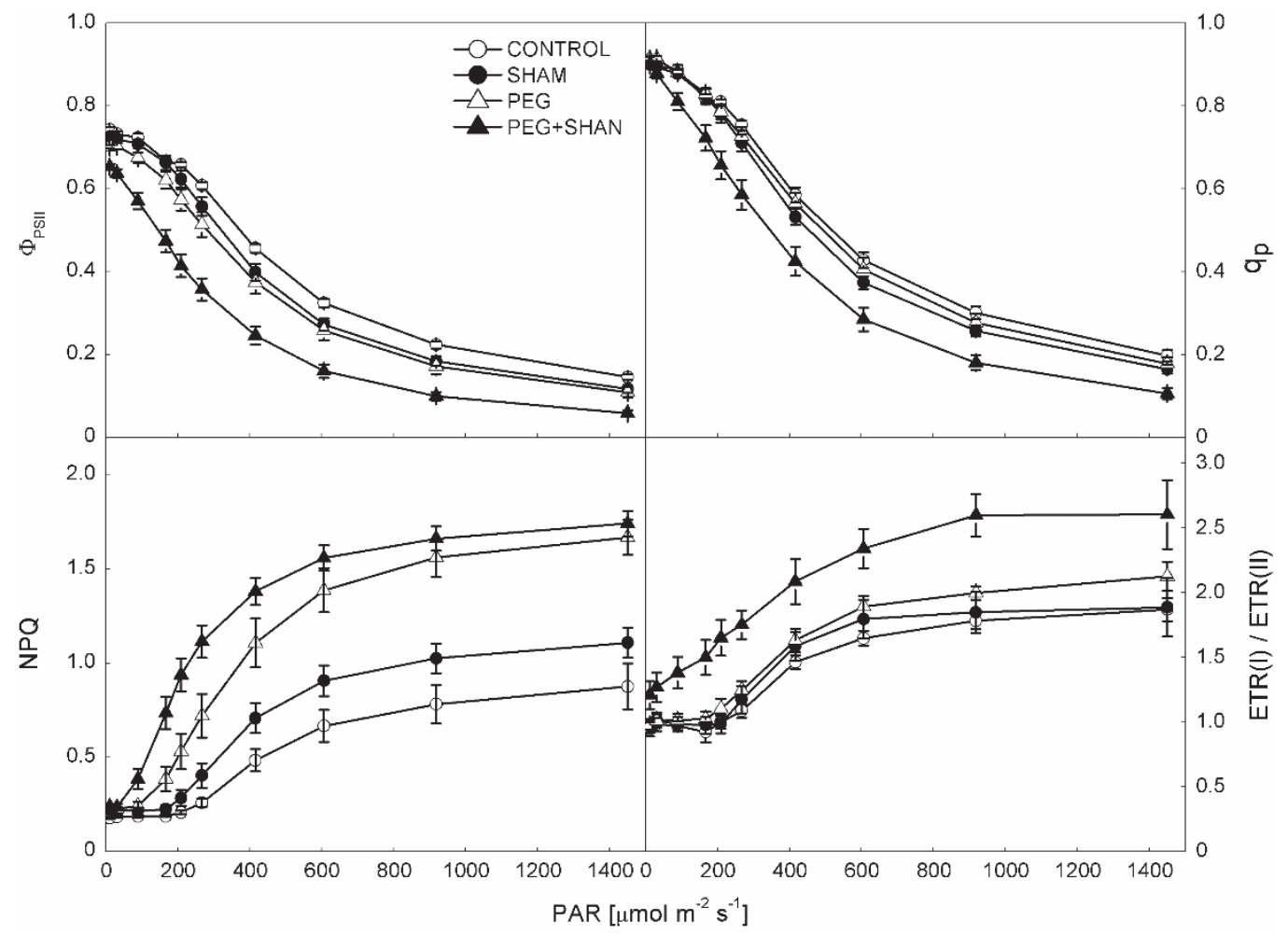

Fig. 1. Effects of PEG and SHAM on RLCs of chlorophyll fluorescence parameters of pepper leaves after four days of treatment. Data represent the means of independent measurements of five replicates with standard errors shown by vertical error bars.

Table 2. Effects of PEG and SHAM on the gas exchange characteristics of pepper leaves after four days of treatment according $P_{\mathrm{N}}-$ PAR response curve. Data are the means of independent measurements of three replicates with standard errors. Values followed by different letters are significant at $0.05 \%$ level.

\begin{tabular}{lllll}
\hline & Control & SHAM & PEG & PEG + SHAM \\
\hline$P_{\max }\left[\mu \operatorname{mol}\left(\mathrm{CO}_{2}\right) \mathrm{m}^{-2} \mathrm{~s}^{-1}\right]$ & $15.5 \pm 0.4^{\mathrm{a}}$ & $8.8 \pm 0.9^{\mathrm{b}}$ & $5.5 \pm 0.7^{\mathrm{c}}$ & $2.9 \pm 0.3^{\mathrm{d}}$ \\
AQY & $0.041 \pm 0.001^{\mathrm{a}}$ & $0.034 \pm 0.003^{\mathrm{b}}$ & $0.020 \pm 0.002^{\mathrm{c}}$ & $0.013 \pm 0.002^{\mathrm{d}}$ \\
$\mathrm{LSP}\left[\mu \operatorname{mol}(\right.$ photon $\left.) \mathrm{m}^{-2} \mathrm{~s}^{-1}\right]$ & $1,830.2 \pm 54.3^{\mathrm{a}}$ & $956.6 \pm 25.8^{\mathrm{b}}$ & $745.8 \pm 49.0^{\mathrm{c}}$ & $598.2 \pm 56.06^{\mathrm{d}}$ \\
\hline
\end{tabular}

Induction curves of $\mathrm{Chl}$ fluorescence parameters: Values of $\Phi_{\text {PSII }}$ and $\mathrm{q}_{\mathrm{P}}$ increased with a delay of approximate $40 \mathrm{~s}$, whereas the increases of NPQ and $\mathrm{ETR}_{(\mathrm{I})} / \mathrm{ETR}_{(\mathrm{II})}$ occurred without a delay. During prolonged illumination, $\mathrm{ETR}_{(\mathrm{I})} / \mathrm{ETR}_{(\mathrm{II})}$ decreased after about $80 \mathrm{~s}$. NPQ also decreased after about $100 \mathrm{~s}$ under normal and drought conditions, however, though it was maintained stable under SHAM and PEG + SHAM treatments.
Drought caused decreases of $\Phi_{\mathrm{PSII}}$ and $\mathrm{q}_{\mathrm{P}}$, but induced the increase of NPQ. SHAM treatment aggravated the decreases of PSII and $\mathrm{q}_{\mathrm{P}}$ and promoted the increase of NPQ in leaves under normal and drought conditions. PEG + SHAM treatment induced the increase of $\mathrm{ETR}_{(\mathrm{I})} / \mathrm{ETR}_{(\mathrm{II})}$, however, drought only induced the increase of $\mathrm{ETR}_{(\mathrm{I})} / \mathrm{ETR}_{(\mathrm{II})}$ during the first illumination time (Fig. 2). 


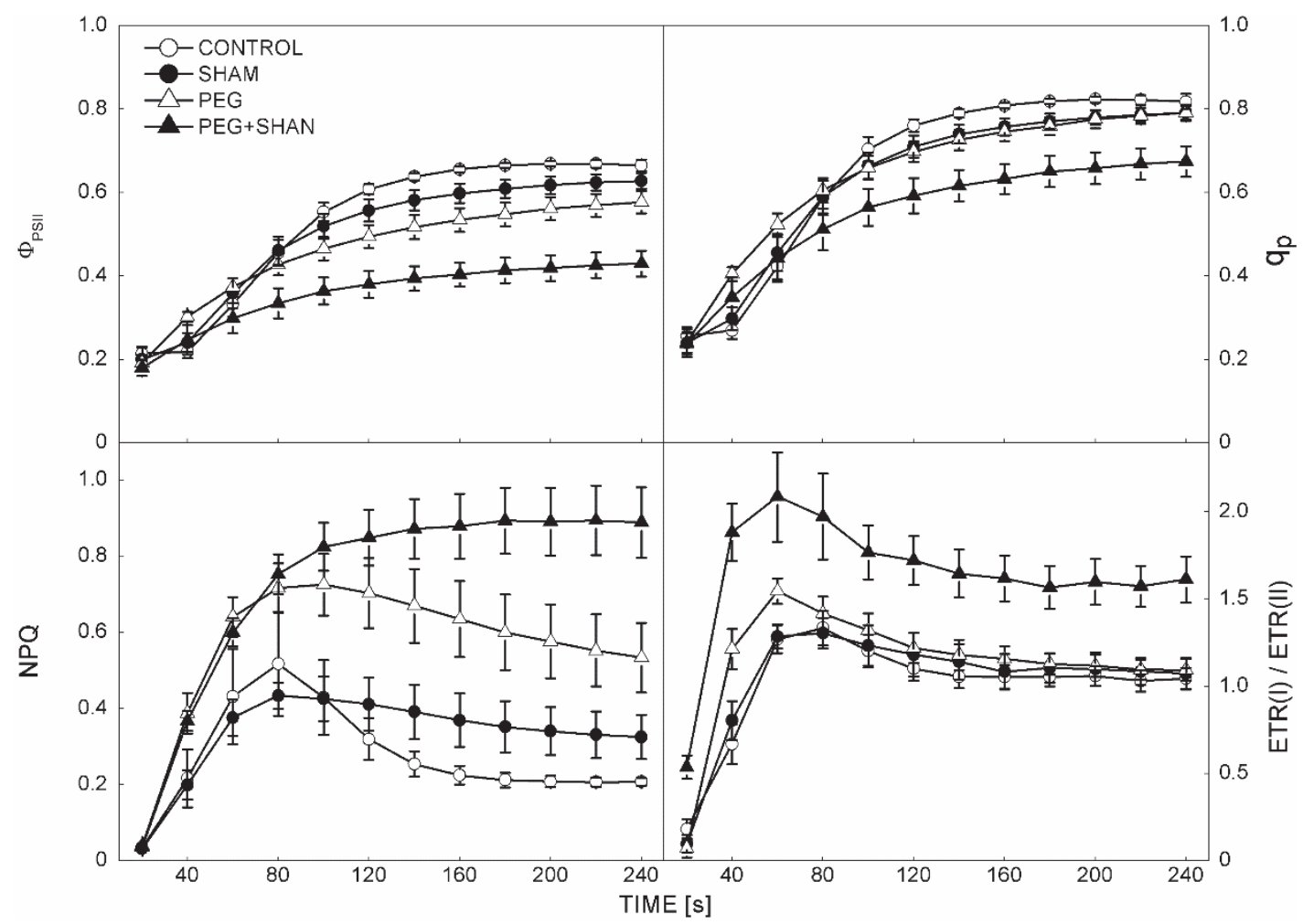

Fig. 2. Effects of PEG and SHAM on induction curves of chlorophyll fluorescence parameters of pepper leaves after $4 \mathrm{~d}$ of treatment. Data represent the means of independent measurements of five replicates with standard errors shown by vertical error bars.

\section{Discussion}

There are reports showing that the AOX pathway is upregulated in plants by a wide range of abiotic stresses (Wagner and Krab 1995, Clifton et al. 2005). The level of AOX proteins and AOX pathway capacity increased in plants subjected to drought (Taylor et al. 2002, Bartoli et al. 2005, $\mathrm{Hu}$ et al. 2010). In the present study, we also observed AOX capacity upregulated by drought (Table 1). AOX pathway is a non-phosphorylating pathway and can efficiently oxidize the excess of reducing equivalents generated in chloroplasts (Gandin et al. 2012, Zhang et al. 2012). In this way, AOX pathway is believed to benefit photosynthesis and protect against photoinhibition by balancing the cellular energy under a variety of environmental conditions (McKenzie and McIntosh 1999, Padmasree et al. 2002, Bartoli et al. 2005, Yoshida et al. 2007). In the present study, that decrease of $F_{v} / F_{m}$ in pepper leaves under drought stress was accompanied by significant decreases of $P_{\mathrm{N}}, P_{\max }$, AQY, and LSP (Fig. 3; Table 1, 2) suggested that drought-induced photoinhibition was partly due to decrease of $\mathrm{CO}_{2}$ assimilaiton. Drought-induced photoinhibition was aggravated by inhibition of the AOX pathway (Table 1). The decreases in $P_{\mathrm{N}}, P_{\max }$, AQY, and LSP were observed in leaves treated by SHAM under drought stress (Fig. 3; Table 2). These results suggested that upregulation of AOX pathway in pepper leaves could protect against drought-induced photoinhibition, which

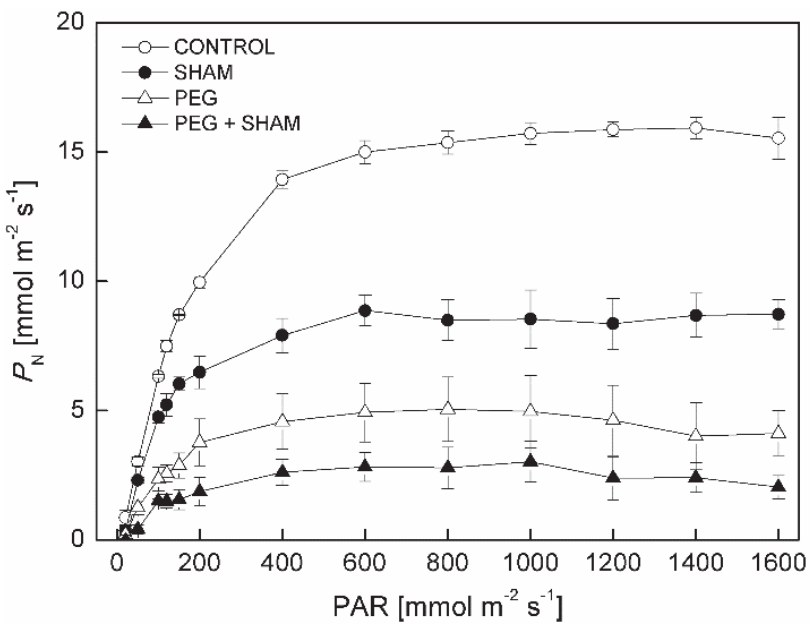

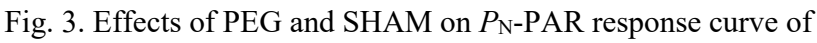
pepper leaves after four days of treatment. Data represent the means of independent measurements of three replicates with standard errors shown by vertical error bars.

was partly due to the optimization of carbon assimilation. Calvin cycle is the main sink of the reducing equivalents produced by photochemical reactions (Tikkanen et al. 2014). We also observed that decreases of $P_{\mathrm{N}}, P_{\max }$, AQY, and LSP in SHAM-treated leaves under normal conditions 
(Fig. 3; Table 2), indicating that AOX pathway is essential for the maintenance of photosynthetic carbon assimilation (Raghavendra and Padmasree 2003).

The photochemical reactions in photosynthesis are among the fastest events, taking place on time scale ranging from tens of femtoseconds to several hundred nanoseconds (Mamedov et al. 2015). However, activation of photosynthetic enzymes requires several minutes (Govindjee and Wasielewski 1989, Eichelmann et al. 2009). Chl fluorescence measurement is rapid, therefore RLCs are able to detect rapid changes in photosynthetic activity, in particular PSII function. In order to probe the effects of carbon assimilation on PSII function and energy dissipation mechanism in chloroplasts, we also measured the induction curves of $\mathrm{Chl}$ fluorescence.

$\Phi_{\text {PSII }}$ is an estimate of the proportion of photons used in photochemistry, and $\mathrm{q}_{\mathrm{P}}$ is an estimate of the proportion of oxidized PSII centers (Maxwell and Johnson 2000, Bartoli et al. 2005). According to RLCs, there was little change in the $\mathrm{q}_{\mathrm{P}}$ and slight decrease of $\Phi_{\mathrm{PSII}}$ in SHAMtreated leaves under normal conditions (Fig. 1), which indicated that AOX pathway was not crucial for photochemical reaction under normal conditions. However, the inhibition of AOX activity caused significant decreases in $\mathrm{q}_{\mathrm{P}}$ and $\Phi_{\mathrm{PSII}}$ in leaves experiencing drought (Fig. 1). We also observed a decline of $\mathrm{q}_{\mathrm{P}}$ and $\Phi_{\mathrm{PSII}}$ in SHAM-treated leaves under drought conditions compared to that under normal conditions according to induction curves (Fig. 2). These results indicate that AOX activity is important in optimizing PSII function and avoiding over-reduction of PSII of plants experiencing drought, which could contribute to the protection against photoinhibition.

Thermal energy dissipation and CEF-PSI mechanisms seem to be operating in leaves exposed to drought (Golding and Johnson 2003, Živčák et al. 2013). If CEFPSI is functioning, $\mathrm{ETR}_{(\mathrm{I})}$ is larger than $\mathrm{ETR}_{(\mathrm{II})}$ (Yamori et

\section{References}

Allakhverdiev S.I.: Recent progress in the studies of structure and function of photosystem II. - J. Photoch. Photobio. B 104: 1-8, 2011.

Allakhverdiev S.I., Klimov V.V., Carpentier R.: Evidence for the involvement of cyclic electron transport in the protection of photosystem II against photoinhibition: influence of a new phenolic compound. - Biochemistry 36: 4149-4154, 1997.

Asada K.: The water-water cycle in chloroplasts: scavenging of active oxygens and dissipation of excess photons. - Annu. Rev. Plant Biol. 50: 601-639, 1999.

Bartoli C.G., Gomez F., Gergoff G. et al.: Up-regulation of the mitochondrial alternative oxidase pathway enhances photosynthetic electron transport under drought conditions. - J. Exp. Bot. 56: 1269-1276, 2005.

Boyer J.S.: Plant productivity and environment. - Science 218: 443-448, 1982.

Clifton R., Lister R., Parker K.L. et al.: Stress-induced coexpression of alternative respiratory chain components in Arabidopsis thaliana. - Plant Mol. Biol. 58: 193-212, 2005. al. 2011). We observed that NPQ and $\mathrm{ETR}_{(\mathrm{I})} / \mathrm{ETR}_{(\mathrm{II})}$ just rapidly increased during the first illumination during induction curves (Fig. 2). This result indicated that thermal energy dissipation and CEF-PSI were the rapid forms of energy dissipation in chloroplasts. This conclusion was supported by the results that NPQ and $\mathrm{ETR}_{(\mathrm{I})} / \mathrm{ETR}_{(\mathrm{II})}$ rapidly increased upon increases in light intensity (Fig. 1). Drought induced higher increase of NPQ than that of $\mathrm{ETR}_{(\mathrm{I})} / \mathrm{ETR}_{(\mathrm{II})}$, however, there was more marked increase of $\mathrm{ETR}_{(\mathrm{I})} / \mathrm{ETR}_{(\mathrm{II})}$ than that of NPQ in SHAM-treated leaves under drought conditions (Fig. 1,2). These results suggested that the decrease in AOX activity could be compensated by increases in thermal energy dissipation and CEFPSI under drought stress, especially CEF-PSI. Although CEF-PSI can serve to protect PSII, the stability of PSI is essential for the stimulation of CEF-PSI (Lei et al. 2014). We observed that $\mathrm{P}_{\mathrm{m}}$ remained stable in leaves under drought with/without the SHAM treatment (Table 1). There were no changes in $F_{v} / F_{m}$ and $\operatorname{ETR}_{(\mathrm{I})} / E R_{(I I)}$, however, the significant increase of NPQ in SHAM treatment under normal conditions (Table 1; Fig. 1, 2), which suggested that AOX pathway could influence chloroplast energy metabolism under normal conditions.

In conclusion, AOX pathway could influence chloroplast energy metabolism and is essential for the maintenance of photosynthetic carbon assimilation in pepper leaves under normal conditions. Drought induced upregulation of the AOX pathway, which plays an important role in protection against drought-induced photoinhibition. AOX pathway could optimize carbon assimilation and PSII function in plants experiencing drought, which could help avoid overreduction of PSII. However, inhibition of AOX pathway could be compensated by increasing the thermal energy dissipation and CEF-PSI under drought stress, and the compensation of CEF-PSI was especially significant.

Dahal K., Martyn G.D., Vanlerberghe G.C.: Improved photosynthetic performance during severe drought in Nicotiana tabacum overexpressing a nonenergy conserving respiratory electron sink. - New Phytol. 208: 382-395, 2015.

Dahal K., Wang J., Martyn G.D. et al.: Mitochondrial alternative oxidase maintains respiration and preserves photosynthetic capacity during moderate drought in Nicotiana tabacum. Plant Physiol. 166: 1560-1574, 2014.

Demmig-Adams B., Adams III.W.W.: The role of xanthophyll cycle carotenoids in the protection of photosynthesis. - Trends Plant Sci. 1: 21-26, 1996.

Eichelmann H., Talts E., Oja V. et al.: Rubisco in planta $k_{\text {cat }}$ is regulated in balance with photosynthetic electron transport. J. Exp. Bot. 60: 4077-4088, 2009.

Erice G., Louahlia S., Irigoyen J.J. et al.: Water use efficiency, transpiration and net $\mathrm{CO}_{2}$ exchange of four alfalfa genotypes submitted to progressive drought and subsequent recovery. Environ. Exp. Bot. 72: 123-130, 2011.

Feng H.Q., Tang S.Z., Sun K. et al.: Cyanide-resistant respiratory 
pathway is involved in the high-light systemic acquired acclimation of kidney bean (Phaseolus vulgaris). - Photosynthetica 53: 195-200, 2015.

Foyer C.H., Vanacker H., Gomez L.D. et al.: Regulation of photosynthesis and antioxidant metabolism in maize leaves at optimal and chilling temperatures: review. - Plant Physiol. Bioch. 40: 659-668, 2002.

Gandin A., Duffes C., Day D.A. et al.: The absence of alternative oxidase AOX1a results in altered response of photosynthetic carbon assimilation to increasing $\mathrm{CO}_{2}$ in Arabidopsis thaliana. - Plant Cell Physiol. 53: 1627-1637, 2012.

Golding A.J., Johnson G.N.: Down-regulation of linear and activation of cyclic electron transport during drought. - Planta 218: 107-114, 2003.

Govindjee, Wasielewski M.R.: Photosystem II: from a femtosecond to a millisecond. - In: Briggs W.R. (ed.): Photosynthesis. Pp. 71-103. Alan R. Liss, New York 1989.

Hu W.H., Xiao Y.A., Zeng J.J. et al.: Photosynthesis, respiration and antioxidant enzymes in pepper leaves under drought and heat stresses. - Biol. Plantarum 54: 761-765, 2010.

Hu W.H., Yan X.H. Yu J.Q.: Importance of the mitochondrial alternative oxidase (AOX) pathway in alleviating photoinhibition in cucumber leaves under chilling injury and subsequent recovery when leaves are subjected to high light intensity. - J. Hort. Sci. Biotech. 92: 31-38, 2017.

Ivanov A.G., Hurry V., Sane P.V. et al.: Reaction centre quenching of excess light energy and photoprotection of photosystem II. - J. Plant Biol. 51: 85-96, 2008.

Jia H., Oguchi R., Hope A.B. et al.: Differential effects of severe water stress on linear and cyclic electron fluxes through photosystem $\mathrm{I}$ in spinach leaf discs in $\mathrm{CO}_{2}$-enriched air. - Planta 228: 803-812, 2008.

Lei Y., Zheng Y., Dai K. et al.: Different responses of photosystem I and photosystem II in three tropical oilseed crops exposed to chilling stress and subsequent recovery. - Trees $\mathbf{2 8}$ : 923-933, 2014.

Mamedov M., Govindjee, Nadtochenko V. et al.: Primary electron transfer processes in photosynthetic reaction centers from oxygenic organisms. - Photosynth. Res. 125: 51-63, 2015.

Maxwell K., Johnson G.N.: Chlorophyll fluorescence - a practical guide. - J. Exp. Bot. 51: 659-668, 2000.

McKenzie S., McIntosh L.: Higher plant mitochondria. - Plant Cell 11: 571-585, 1999.

Mohanty P., Allakhverdiev S.I., Murata N.: Application of low temperatures during photoinhibition allow characterization of individual steps in photodamage and the repair of photosystem II. - Photosynth. Res. 94: 217-224, 2007

Nunes-Nesi A., Sulpice R., Gibon Y. et al.: The enigmatic contribution of mitochondrial function in photosynthesis. - J. Exp. Bot. 59: 1675-1684, 2008.

Ort D.R., Baker N.R.: A photoprotective for $\mathrm{O}_{2}$ as an alternative electron sink in photosynthesis. - Curr. Opin. Plant Biol. 5: 193-198, 2002.

Padmasree K., Padmavathi L., Raghavendra A.S.: Essentiality of mitochondrial oxidative metabolism for photosynthesis: optimization of carbon assimilation and protection against photoinhibition. - Crit. Rev. Biochem. Mol. Biol. 37: 71-119, 2002.

Raghavendra A.S., Padmasree K.: Beneficial interactions of mitochondrial metabolism with photosynthetic carbon assimilation. - Trends Plant Sci. 8: 546-553, 2003.

Song X.S., Shang Z.W., Yin Z.P. et al.: Mechanism of xanthophyll-cycle-mediated photoprotection in Cerasus humilis seedlings under water stress and subsequent recovery. - Photosynthetica 49: 523-530, 2011.

Taylor N.L., Day D.A., Millar A.H.: Environmental stress causes oxidative damage to plant mitochondrial leading to inhibition to glycine decarboxylase. - J. Biol. Chem. 277: 42663-42668, 2002.

Tikkanen M., Mekala N.R., Aro E.M.: Photosystem II photoinhibition-repair cycle protects photosystem I from irreversible damage. - BBA-Bioenergetics 1837: 210-215, 2014.

Wagner A.M., Krab K.: The alternative respiration pathway in plants: role and regulation. - Physiol. Plant. 95: 318-325, 1995.

Walker B.J., Strand D.D., Kramer D.M. et al.: The response of cyclic electron flow around photosystem I to changes in photorespiration and nitrate assimilation. - Plant Physiol. 165: 453-462, 2014.

Yamori W., Sakata N., Suzuki Y. et al.: Cyclic electron flow around photosystem I via chloroplast $\mathrm{NAD}(\mathrm{P}) \mathrm{H}$ dehydrogenase (NDH) complex performs a significant physiological role during photosynthesis and plant growth at low temperature in rice. - Plant J. 68: 966-976, 2011.

Ye Z.P.: A new model for relationship between irradiance and the rate of photosynthesis in Oryza sativa. - Photosynthetica 45: 637-640, 2007.

Yin C.Y., Peng Y.H., Zang R.G. et al.: Adaptive responses of Populus kangdingensis to drought stress. - Physiol. Plantarum 123: 445-451, 2005.

Yoshida K., Terashima I., Noguchi K.: Distinct roles of the cytochrome pathway and alternative oxidase in leaf photosynthesis. - Plant Cell Physiol. 47: 22-31, 2006.

Yoshida K., Terashima I., Noguchi K.: Up-regulation of mitochondrial alternative oxidase concomitant with chloroplast over-reduction by excess light. - Plant Cell Physiol. 48: 606614, 2007.

Yu J.Q., Matsui Y.: Effects of root exudates and allelochemical on ion uptake by cucumber seedlings. - J. Chem. Ecol. 23: 817827, 1997.

Zandalinas S.I., Rivero R.M., Martínez V. et al.: Tolerance of citrus plants to the combination of high temperatures and drought is associated to the increase in transpiration modulated by a reduction in abscisic acid levels. - BMC Plant Biol. 16: 105, 2016.

Zhang L.T., Zhang Z.S., Gao H.Y. et al.: The mitochondrial alternative oxidase pathway protects the photosynthetic apparatus against photodamage in Rumex K-1 leaves. - BMC Plant Biol. 12: 40, 2012.

Zhang L.T., Zhang Z.S., Gao H.Y. et al.: Mitochondrial alternative oxidase pathway protects plants against photoinhibition by alleviating inhibition of the repair of photodamaged PSII through preventing formation of reactive oxygen species in Rumex K-1 leaves. - Physiol. Plantarum 143: 396-407, 2011.

Živčák M., Brestic M., Balatova Z. et al.: Photosynthetic electron transport and specific photoprotective response in wheat leaves under drought stress. - Photosynth. Res. 117: 529-546, 2013. 